\title{
Protein synthesis in the amygdala, but not the auditory thalamus, is required for consolidation of Pavlovian fear conditioning in rats
}

\author{
Stephen Maren, ${ }^{1,3}$ Carrie R. Ferrario, ${ }^{3}$ Kevin A. Corcoran, ${ }^{1}$ Timothy J. Desmond ${ }^{2}$ and Kirk A. Frey ${ }^{2,3}$ \\ ${ }^{1}$ Department of Psychology, University of Michigan, 525E. University Avenue, Ann Arbor, Ml 48109-1109 \\ ${ }^{2}$ Departments of Radiology and Neurology, University of Michigan, Ann Arbor, MI 48109-0720 \\ ${ }^{3}$ Neuroscience Program, University of Michigan, Ann Arbor, MI 48109-0520
}

Keywords: NMDA receptor, protein kinase, anisomycin, medial geniculate body, memory, freezing

\begin{abstract}
The amygdala is an essential neural substrate for Pavlovian fear conditioning. Nevertheless, long-term synaptic plasticity in amygdaloid afferents, such as the auditory thalamus, may contribute to the formation of fear memories. We therefore compared the influence of protein synthesis inhibition in the amygdala and the auditory thalamus on the consolidation of Pavlovian fear conditioning in LongEvans rats. Rats received three tone-footshock trials in a novel conditioning chamber. Immediately after fear conditioning, rats were infused intra-cranially with the protein synthesis inhibitor, anisomycin. Conditional fear to the tone and conditioning context was assessed by measuring freezing behaviour in separate retention tests conducted at least $24 \mathrm{~h}$ following conditioning. Post-training infusion of anisomycin into the amygdala impaired conditional freezing to both the auditory and contextual stimuli associated with footshock. In contrast, intra-thalamic infusions of anisomycin or a broad-spectrum protein kinase inhibitor [1-(5'-isoquinolinesulphonyl)2-methylpiperazine, $\mathrm{H} 7$ ] did not affect conditional freezing during the retention tests. Pre-training intra-thalamic infusion of the NMDA receptor antagonist 2-amino-5-phosphonopentanoic acid (APV), which blocks synaptic transmission in the auditory thalamus, produced a selective deficit in the acquisition of auditory fear conditioning. Autoradiographic assays of cerebral $\left[{ }^{14} \mathrm{C}\right]$-leucine incorporation revealed similar levels of protein synthesis inhibition in the amygdala and thalamus following intra-cranial anisomycin infusions. These results reveal that the establishment of long-term fear memories requires protein synthesis in the amygdala, but not the thalamus, after auditory fear conditioning. Forms of synaptic plasticity that depend on protein synthesis, such as long-term potentiation, are likely candidates for the encoding and long-term storage of fear memories in the amygdala.
\end{abstract}

\section{Introduction}

Considerable interest has emerged in recent years in the neural mechanisms of Pavlovian fear conditioning, a model system for studying emotional learning and memory (Fendt \& Fanselow, 1999; Davis, 2000; LeDoux, 2000; Maren, 2001). During fear conditioning, rats learn that an innocuous stimulus (the conditional stimulus or CS), such as a tone, predicts the occurrence of an aversive stimulus (the unconditional stimulus or US), such as a footshock. Conditional fear is expressed in a variety of behavioural responses, including freezing. Several lines of evidence indicate that neurons in the basolateral amygdala (BLA) are essential for fear conditioning and this has led to the proposal that synaptic plasticity in the amygdala is critical for the encoding and long-term storage of the CS-US associations that underlie fear conditioning (Maren \& Fanselow, 1996; Fanselow \& LeDoux, 1999; Maren, 1999a).

Recent studies have shed light on the molecular mechanisms involved in the induction and stabilization of long-term fear memory in the amygdala (Blair et al., 2001; Schafe et al., 2001). These mechanisms involve the activation of membrane bound proteins including NMDA receptors and voltage-gated calcium channels (Bauer et al.,

Correspondence: Dr Stephen Maren, as above.

E-mail: maren@umich.edu

Received 13 June 2003, revised 3 October 2003, accepted 7 October 2003
2002), calcium-dependent kinases including protein kinase A (PKA) and mitogen-activated protein kinase (MAPK) (Goosens et al., 2000; Schafe \& LeDoux, 2000; Lin et al., 2001), and transcriptional regulators such as cyclic AMP response-element binding protein (Impey et al., 1998; Josselyn et al., 2001). Ultimately, these cascades yield new protein synthesis to support the long-term changes in synaptic function, such as long-term potentiation (LTP), that are believed to underlie fear memory in the amygdala (Maren, 1999a). Consistent with this view, inhibition of protein synthesis in the amygdala with anisomycin profoundly disrupts both fear memory consolidation and amygdaloid LTP (Huang \& Kandel, 1998; Huang et al., 2000; Nader et al., 2000; Schafe \& LeDoux, 2000).

Despite the wealth of data implicating the amygdala in fear conditioning, there are many other brain structures that exhibit neuronal plasticity during fear conditioning. In auditory fear conditioning, for example, plasticity in the auditory thalamus, the primary auditory afferent of the amygdala, is well documented (Weinberger, 1998). For example, associative spike firing develops in the medial geniculate nucleus of the thalamus (MGN) during aversive conditioning (Gabriel et al., 1975; Supple \& Kapp, 1989; Edeline \& Weinberger, 1992), MGN neurons exhibit LTP (Gerren \& Weinberger, 1983), and synaptic plasticity occurs in the MGN during fear conditioning (McEchron et al., 1996). Moreover, auditory thalamic lesions disrupt auditory fear conditioning (Jarrell et al., 1986; LeDoux et al., 1986; Campeau \& 
Davis, 1995; Poremba \& Gabriel, 1997; Brunzell \& Kim, 2001). Thus, synaptic plasticity in the auditory thalamus may be important in the acquisition of Pavlovian fear conditioning, at least to auditory stimuli. Yet in spite of the evidence suggesting a role for the MGN in auditory Pavlovian fear conditioning, the molecular processes in the auditory thalamus that might contribute to fear memory have not been studied. As a first step in addressing this issue, we used intra-cranial infusions of a broad-spectrum protein kinase inhibitor [1-(5'-isoquinolinesulphonyl)-2-methylpiperazine, H7] and a protein synthesis inhibitor (anisomycin) to examine whether protein kinase activation and protein synthesis in the auditory thalamus are necessary for the induction of auditory fear memories in rats.

\section{Materials and methods}

The subjects were 68 adult male Long-Evans rats (200-225 g) obtained from a commercial supplier (Harlan Sprague-Dawley, Indianapolis, IN). The rats were individually housed in Plexiglas cages on a 14-h light : 10-h dark cycle (lights on at $07.00 \mathrm{~h}$ ), provided free access to food and water, and handled daily. All procedures were approved by the University of Michigan UCUCA (University Committee on the Use and Care of Animals).

Prior to behavioural testing, rats were anaesthetized with Nembutal (sodium pentobarbital, $65 \mathrm{mg} / \mathrm{kg}$, i.p.) and implanted with bilateral guide cannulae (stainless steel, 23-g) aimed at the MGN $(6.0 \mathrm{~mm}$ posterior and $3.1 \mathrm{~mm}$ lateral to bregma; $5.5 \mathrm{~mm}$ ventral to dura) or the BLA ( $2.3 \mathrm{~mm}$ posterior and $5.0 \mathrm{~mm}$ lateral to bregma; $6.3 \mathrm{~mm}$ ventral to dura). Rats receiving BLA implants were assigned to one of two groups. One group of rats (BL-PBS, $n=14$ ) received intra-BLA infusions of phosphate-buffered saline (PBS) immediately after fear conditioning. A second group of rats (BL-ANISO, $n=10$ ) received intra-BLA infusions of anisomycin $(125 \mu \mathrm{g} / \mu \mathrm{L}$ in $1 \mathrm{M} \mathrm{HCl}$ and $100 \mathrm{~mm}$ PBS, pH 7.2) immediately after fear conditioning. All infusions were delivered at a rate of $0.1 \mu \mathrm{L} / \mathrm{min}$ for $5 \mathrm{~min}(0.5 \mu \mathrm{L}$ per hemisphere) through 28-g injectors that extended 1-mm beyond the tip of the guide cannulae. The injectors were connected to Hamilton syringes with polyethylene tubing, and the syringes were mounted in an infusion pump (Harvard Apparatus, South Natick, MA). One minute was allowed for diffusion before removing the injectors. The dose of anisomycin we used has previously been reported to block the consolidation of fear memories (Nader et al., 2000; Schafe \& LeDoux, 2000). The anisomycin was delivered in a saturated solution $(471 \mathrm{mM})$ and is a maximal dose at the volume we infused.

Rats receiving MGN implants were assigned to one of five groups. One group of control rats (MG-SAL, $n=8$ ) received intra-thalamic infusions of sterile saline $(0.9 \%)$ immediately before fear conditioning. A second group of control rats (MG-PBS, $n=7$ ) received intrathalamic infusions of a $50: 50(\mathrm{v}: \mathrm{v})$ solution of $100 \mathrm{mM}$ phosphatebuffered saline and $1 \mathrm{M} \mathrm{HCl}$ (PBS, $\mathrm{pH} 7.2$ ) immediately after fear conditioning. A third group of rats (MG-APV, $n=8$ ) received the NMDA receptor antagonist D,L-2-amino-5-phosphonopentanoic acid (APV, $5 \mu \mathrm{g} / \mu \mathrm{L}$ in saline), immediately before fear conditioning. A fourth group of rats $(\mathrm{MG}-\mathrm{H} 7, n=10)$ received the broad-spectrum protein kinase inhibitor, 1-(5'-isoquinolinesulphonyl)-2-methylpiperazine dihydrochloride $(\mathrm{H} 7,5 \mu \mathrm{g} / \mu \mathrm{L}$ in saline), immediately before fear conditioning. A fifth group of rats (MG-ANISO, $n=8)$ received intra-MGN infusions of anisomycin $(125 \mu \mathrm{g} / \mu \mathrm{L}$ in $1 \mathrm{M} \mathrm{HCl}$ and $100 \mathrm{~mm}$ PBS, $\mathrm{pH}$ 7.2) immediately after fear conditioning. The doses of APV and $\mathrm{H} 7$ are effective in attenuating fear conditioning when infused into the BLA (Lee \& Kim, 1998; Goosens et al., 2000). All drugs were obtained from Sigma-Aldrich (Sigma-Aldrich, St. Louis, $\mathrm{MO})$.
For fear conditioning, rats were transported to conditioning chambers $(30 \times 24 \times 40 \mathrm{~cm}$; MED-Associates, Burlington, VT) that were equipped for the delivery of auditory CSs $(2000 \mathrm{~Hz}, 85 \mathrm{~dB}, 10 \mathrm{~s})$ and footshock USs $(1.0 \mathrm{~mA}, 2.0 \mathrm{~s})$ [see Maren, (1999b) for a detailed description of the apparatus and contexts]. Fear conditioning consisted of the delivery of three tone-footshock trials ( $70 \mathrm{~s}$ intertrial interval) that began $3 \mathrm{~min}$ after the rats were placed in the chambers (Context A). Conditional fear was assessed in two retention tests administered 24 and $48 \mathrm{~h}$ following conditioning. In the tone extinction test, rats were transported to the same chambers that were modified to yield a novel context (Context B). Two minutes after the rats were placed in the chambers a continuous 8-min auditory CS was presented. The next day, the rats were returned to the original conditioning context (Context A) for a 10-min context extinction test. In both tests, freezing served as the measure of fear.

Freezing was measured by continuously monitoring each rat's activity using load cells under the conditioning chambers. For each chamber, load-cell activity (range 0-100) was digitized at $5 \mathrm{~Hz}$ yielding one observation per rat every $200 \mathrm{~ms}$ (300 observations/rat/ min). In all experiments, freezing was quantified by computing the number of observations for each rat that had a value less than the freezing threshold [load cell activity $\leq 5$; see Maren, (1998)]. To avoid counting momentary inactivity as freezing, an observation was only scored as freezing if it fell within a contiguous group of at least five observations that were all less than the freezing threshold. Thus, freezing was only scored if the rat was immobile for at least one second. For each session, the freezing observations were transformed to a percentage of total observations. In addition to freezing, motor activity was quantified during the pre-shock period on the conditioning day using the raw load-cell output.

After behavioural testing, the rats were perfused and the brain was removed, frozen and sectioned on a cryostat. The sections were stained with $0.25 \%$ thionin to visualize neuronal cell bodies and the cannula tracks. Cannula placements were verified by reconstructing the cannula tracks on stereotaxic atlas templates. A total of 15 rats were excluded because of inaccurate cannula placements leaving the following groups: BL-PBS $(n=8)$, BL-ANISO $(n=7)$, MG-PBS $(n=7)$, MG-ANISO $(n=7)$, MG-SAL $(n=7)$, MG-APV $(n=7)$, and MG-H7 $(n=7)$.

Statistical analysis of the behavioural data was performed using analysis of variance (ANOVA). Repeated measures ANOVAs were performed for comparisons between the experimental groups and their respective control groups for freezing during the conditioning session and during the context and tone extinction tests. Planned comparisons in the form of Fisher LSD tests were performed after obtaining significant omnibus $F \mathrm{~s}$ in the ANOVAs. In the ANOVA for the conditioning session data, infusion group (VEH, ANISO, H7 or APV) was a between-subjects variable and period ( 3 min pre-shock period and three post-shock minutes) was a within-subjects variable. In the ANOVA for the retention test data, infusion condition (VEH, ANISO, H7 or APV) was a between-subjects variable and both CS modality (tone or context) and test minute (the 8-min period after onset of the tone CS or the first $8 \mathrm{~min}$ of the context test) were within-subjects variables. In all cases, separate ANOVAs were performed on animals receiving post-training anisomycin (BL-ANISO, $n=7$ ) or vehicle infusions into the BLA (BL-PBS, $n=8$ ), posttraining anisomycin (MG-ANISO, $n=7$ ) or vehicle infusions into the MGN (MG-PBS, $n=7$ ), and pre-training infusions of either vehicle (MG-SAL, $n=7$ ), H7 (MG-H7, $n=7$ ) or APV (MG-APV, $n=7$ ) into the MGN. For clarity of presentation, the vehicle-infused groups were collapsed to form a single control $(\mathrm{CON}, n=22)$ group in the figures. 
In a separate experiment, we used autoradiographic techniques to assess the effect of intra-thalamic and intra-amygdala anisomycin on the incorporation of systemically injected radiolabelled leucine, which indexes new protein synthesis (Eichenbaum et al., 1973; Smith et al., 1984). In three rats, we made infusions of anisomycin $(62.5 \mu \mathrm{g}$ in $0.5 \mu \mathrm{L} ; 471 \mathrm{mM}$ ) into both the auditory thalamus and contralateral amygdala one hour prior to an intravenous (tail vein) injection of $\left[{ }^{14} \mathrm{C}\right]$-leucine $\left[30 \mu \mathrm{Ci}(100 \mu \mathrm{Ci} / \mathrm{kg}) \mathrm{L}-\left[1-{ }^{14} \mathrm{C}\right]\right.$-leucine in $0.1 \mathrm{~mL}$; New England Nuclear, Boston, MA]. Sixty minutes after the $\left[{ }^{14} \mathrm{C}\right]$-leucine injection the rats were decapitated and their brains were rapidly removed and frozen. Coronal sections $(20 \mu \mathrm{m})$ were cut on a cryostat, affixed to chilled microscope slides, and then rapidly dessicated on a hotplate. The dried sections were opposed to X-ray film (Amersham Beta-Max Hyperfilm; Amersham Biosciences, Piscataway, NJ) together with calibrated plastic radioactive standards for six weeks. The autoradiograms were processed with Kodak D-19 developer and Rapid Fixer according to the manufacturer's recommendations. A computer-assisted image analysis system (MCID Elite, Imaging Research, Inc., St. Catherine's, Ontario, Canada) was used to quantify optical density in the amygdala and auditory thalamus in the infused and control (uninfused) hemispheres of each rat. Optical density values were converted to apparent tissue radioactivity concentrations on the basis of the calibrated standards (Smith et al., 1984), and tracer activity was calculated in regions of interest in serial sections that included the injection cannula (target section) and three sections that extended both rostral and caudal to the target section ( $200 \mu \mathrm{m}$ intervals; i.e. $600 \mu \mathrm{m}$ rostral and caudal to the injection site). The tissue was subsequently stained with cresyl violet to visualize neuronal cell bodies in the region of the infusions.

\section{Results}

\section{Cannula placements}

Cannula placements in the auditory thalamus and amygdala are shown in Fig. 1. Placements in the auditory thalamus were bilaterally symmetrical and centred on the medial division of the MGN. Placements in the amygdala were centred in the lateral and basolateral nuclei of the amygdala. There were no group differences in the pattern of placements in either the auditory thalamus or amygdala.

\section{Behaviour}

Conditional freezing during the fear conditioning session is shown in Fig. 2. For clarity, the vehicle control groups were collapsed to form a single control group $(\mathrm{CON})$, although the statistical comparisons were made for each experimental group relative to its respective control group. Animals scheduled to receive post-training anisomycin infusions into the amygdala or auditory thalamus did not differ from their respective control groups. There were nonsignificant main effects of infusion group (BLA: $F_{1,13}=0.01, P=0.91$; MGN: $F_{1,12}=0.07$, $P=0.79)$ and nonsignificant interactions of infusion group and period (BLA: $F_{3,39}=0.63, P=0.60$; MGN: $F_{3,27}=1.4, P=0.28$ ) in each ANOVA. This is not surprising insofar as these groups had been treated identically to that point in training. Likewise, animals receiving

\section{MGN}

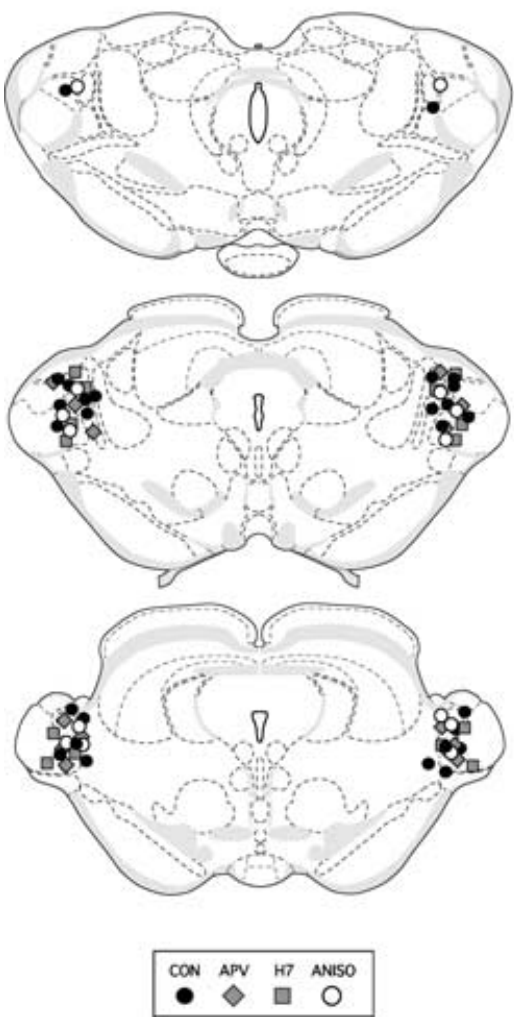

BLA

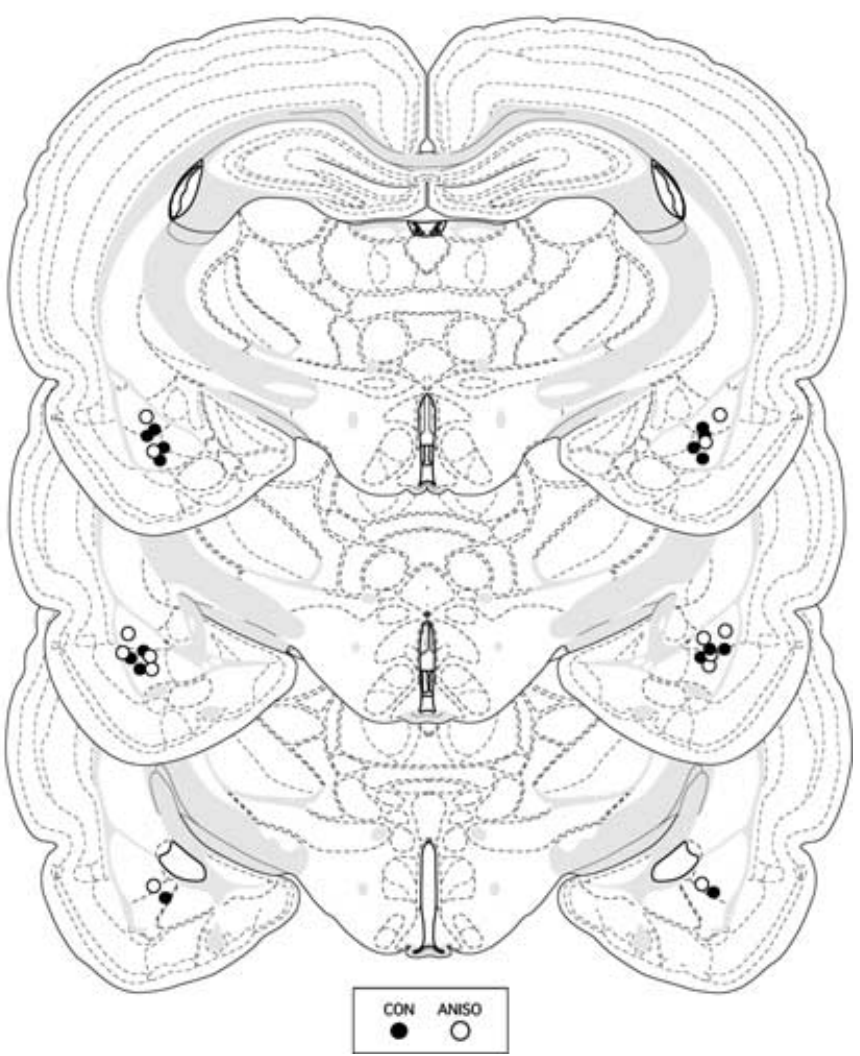

FIG. 1. Schematic illustration of cannula placements in the medial geniculate nucleus of the thalamus (MGN) and the basolateral amygdala (BLA). From top to bottom, the stereotaxic coordinates (mm relative to bregma) for each panel are: MGN, $-5.25,-5.65$, and -6.06 ; BLA, $-2.45,-2.85$, and -3.25 . Stereotaxic templates were adapted from Swanson, (1998). 


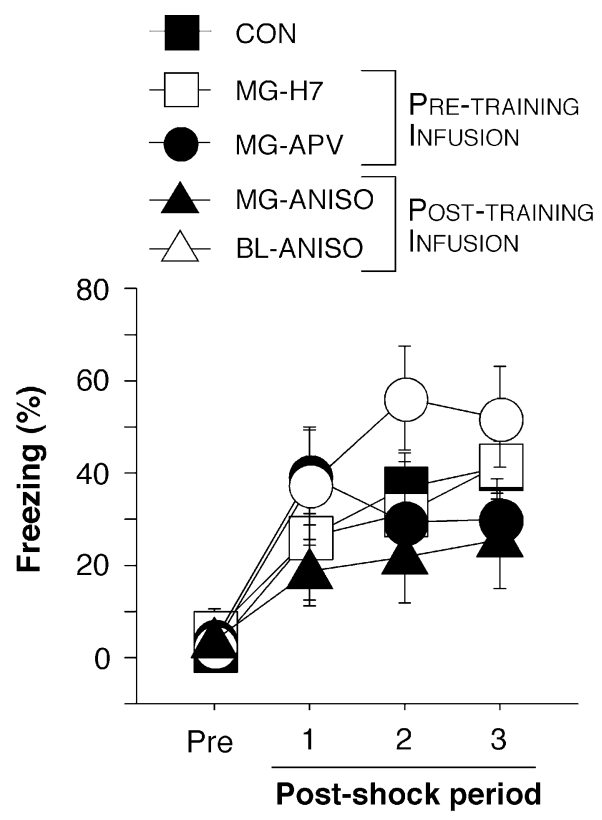

FIG. 2. Mean $( \pm$ SEM) percentage of freezing during 6 min conditioning session. The graph shows freezing averaged across the 3-min pre-trial period (Pre) and during each of the three $60 \mathrm{~s}$ post-shock periods after each conditioning trial. All drug infusions occurred either immediately before fear conditioning (pre-training infusions) or immediately after fear conditioning (post-training infusions). All groups showed similar levels of post-shock freezing during the conditioning session.

pre-training infusions of $\mathrm{H} 7$ or APV into the auditory thalamus did not differ from controls receiving pre-training infusions of saline into the thalamus (main effect of infusion group: $F_{2,18}=0.13, P=0.87$; interaction of infusion group and period: $F_{6,54}=0.77, P=0.60$ ). Hence, all groups exhibited equivalent levels of post-shock freezing prior to the retention tests conducted 24 and $48 \mathrm{~h}$ after conditioning. Importantly, neither inhibition of protein kinase activity nor NMDA receptor activity in the auditory thalamus affected post-shock freezing on the conditioning day.

Conditional freezing during the tone and context extinction tests is shown in Fig. 3. For clarity, the vehicle groups were collapsed to form a single control group (CON). Post-training infusions of anisomycin into the amygdala severely attenuated conditional freezing to both the tone $\mathrm{CS}$ and the conditioning context. This observation was confirmed by a significant main effect of infusion group in the ANOVA $\left(F_{1,13}=4.85\right.$, $P<0.05)$. There was not a significant interaction between infusion group and CS modality $\left(F_{1,13}=0.25, P=0.63\right)$, indicating that the effect of anisomycin on conditional freezing was similarly severe for the tone and context extinction tests. In contrast, intra-thalamic infusions of anisomycin did not affect the retention of conditional freezing during either the tone or context extinction test. In support of this observation, there was not a main effect of infusion group $\left(F_{1,12}=0.04, P=0.84\right)$, nor an interaction of infusion group with either CS modality $\left(F_{1,12}=0.07, P=0.79\right)$ or CS modality and test minute $\left(F_{7,84}=0.68, P=0.69\right]$ in the ANOVA. Thus, post-training protein synthesis in the amygdala, but not auditory thalamus, is involved in the consolidation of long-term fear memories.

Protein kinase activation is associated with the induction of longterm memory, and we have previously shown that intra-amygdaloid infusion of $\mathrm{H} 7$, a broad-spectrum protein kinase inhibitor, disrupts the acquisition of fear conditioning (Goosens et al., 2000). Consequently, we examined whether pre-training infusions of $\mathrm{H} 7$ into the MGN disrupt the acquisition of conditional freezing. To demonstrate that our intra-thalamic infusions of anisomycin and $\mathrm{H} 7$ were made in a region of the auditory thalamus that is critical for auditory fear conditioning, we also infused the NMDA receptor antagonist, APV, into the MGN prior to fear conditioning. NMDA receptors in the auditory thalamus play an important and constitutive role in normal synaptic transmission in the MGN. For example, an APV infusion into the auditory thalamus reduces the single-unit activity evoked by inferior colliculus stimulation (Webber et al., 1999). We therefore expected that pre-training
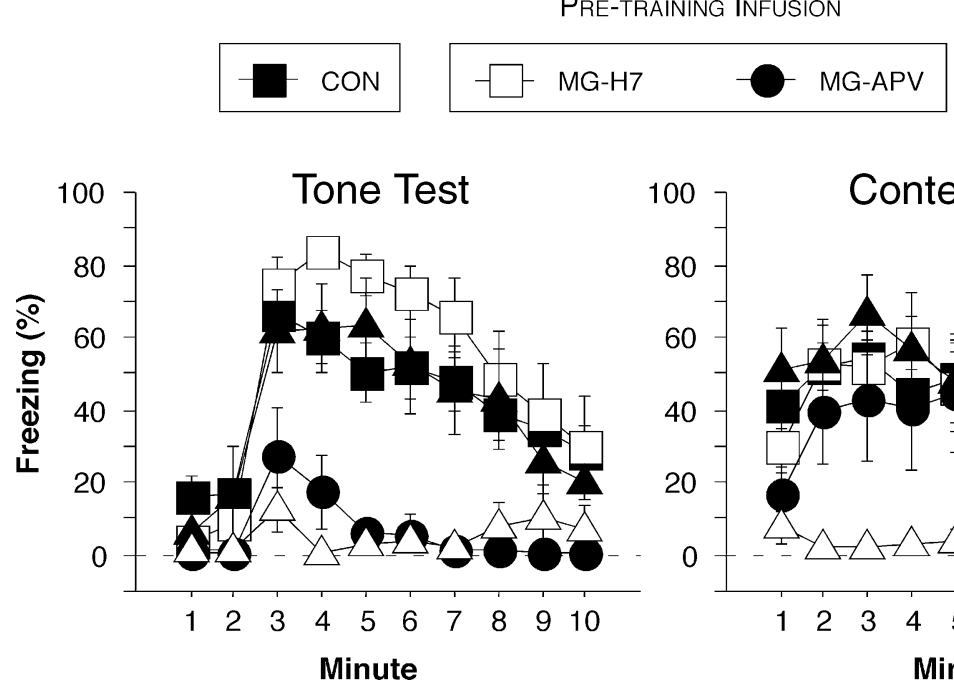
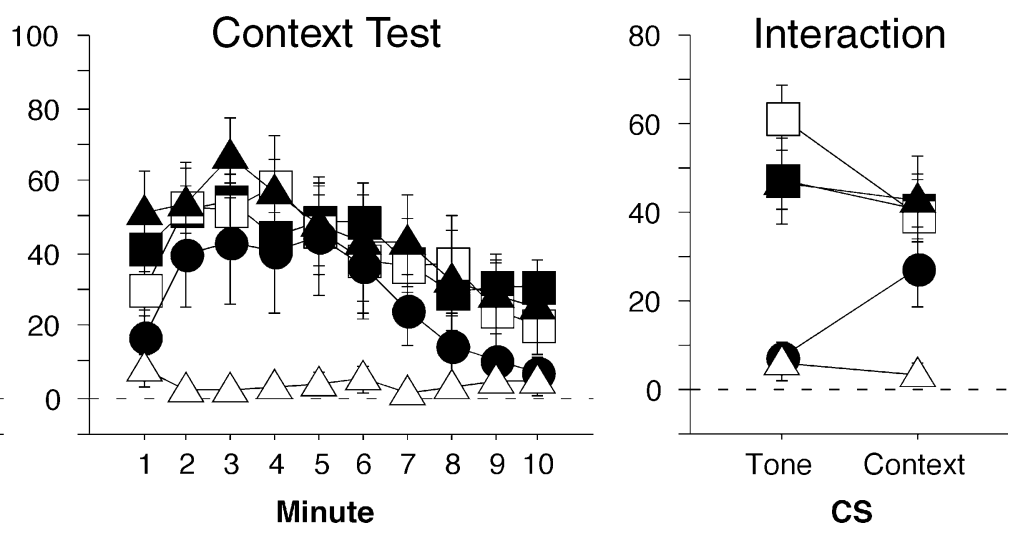

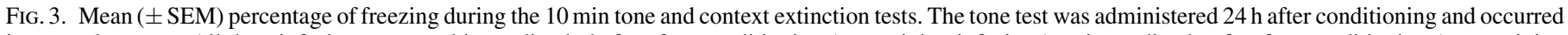

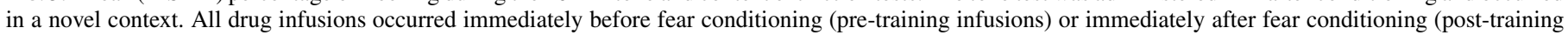

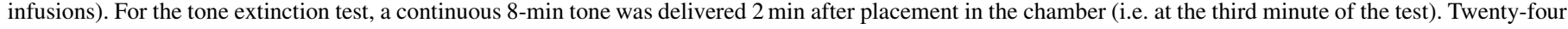

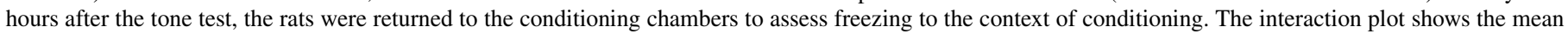

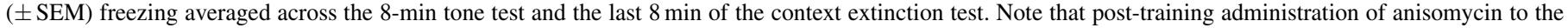

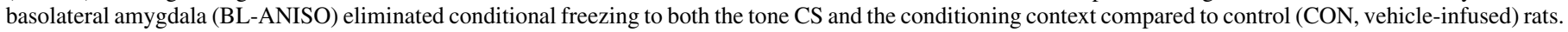

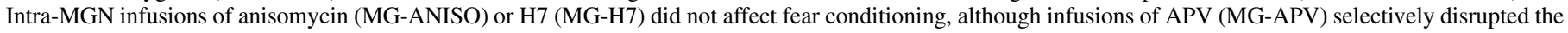
acquisition of auditory fear conditioning. 
infusion of APV into the MGN would selectively attenuate auditory fear conditioning by preventing transmission of auditory information to the amygdala.

As shown in Fig. 3, rats receiving intra-thalamic $\mathrm{H} 7$ infusions prior to fear conditioning did not exhibit deficits in conditional freezing during later retention testing. In contrast, rats receiving intra-thalamic infusions of APV exhibited a selective deficit in freezing to the auditory CS. These observations were confirmed by a significant main effect of infusion group $\left(F_{2,18}=12.6, P<0.0005\right)$ and a significant drug by $C S$ modality interaction $\left(F_{2,18}=7.54, P<0.005\right)$ in the ANOVA. Planned comparisons $(P<0.05)$ indicated that rats receiving pre-training intra-thalamic APV infusions exhibited significantly less tone freezing than rats receiving either saline or $\mathrm{H} 7$; context freezing among the groups was not significantly different. This outcome confirms that our intra-thalamic drug manipulations targeted a region of the auditory thalamus that is critical for auditory fear conditioning. Moreover, it confirms that the auditory thalamus plays an essential role in relaying auditory information to the amygdala for the establishment of the CS-US associations that support long-term fear memory. However, our data reveal that, whereas NMDA receptor-dependent synaptic transmission in the MGN is selectively involved in the acquisition of auditory fear conditioning, protein kinase-dependent and protein synthesis-dependent synaptic plasticity is not. Therefore, long-term synaptic plasticity in the auditory thalamus, which presumably requires both protein kinase activation and new protein synthesis, is not involved in the acquisition or consolidation of the long-term fear memories responsible for context-elicited and CS-elicited freezing behaviour.

The pattern of deficits in BL-ANISO rats is similar to that in rats with post-training BLA lesions (Maren, 1999b). Histological analysis of the tissue did not reveal tissue damage in anisomycin-infused rats, and rats in the MG-ANISO group never exhibited deficits in conditional freezing. Nonetheless, it is possible that anisomycin infusion into the amygdala exerted its effects by permanently disrupting amygdala function, rather than temporarily inhibiting protein synthesis. To address this issue, we gave the rats in the BL-ANISO and MG-ANISO [along with a subset of the controls, CON $(n=15)$ ] five additional training trials in the absence of post-training drug infusion. As shown in Fig. 4, rats in the BL-ANISO group acquired normal levels of auditory and contextual freezing after additional, drug-free

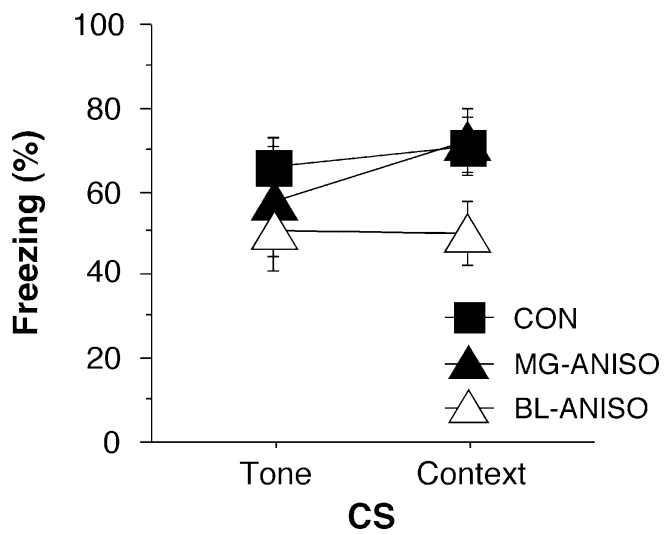

FIG. 4. Mean $( \pm$ SEM) percentage of freezing averaged across the tone and context extinction tests conducted 24 and $48 \mathrm{~h}$, respectively, after five additional training trials in a subset of the rats shown in Fig. 2. Note that these rats did not receive drug treatments after the additional training trials; the group designations refer only to the group designations in Fig. 2, not to actual drug treatments. These data indicate that the deficits in BL-ANISO rats shown in Fig. 2 were not due to enduring dysfunction produced by intra-BLA anisomycin infusions. conditioning trials. There was neither a significant main effect of infusion group nor an infusion group by CS modality interaction in the ANOVA performed on these data $(F \mathrm{~s}<1.7)$. Hence, these data indicate that anisomycin infusions produced a transient memory-impairing effect when administered shortly after the original conditioning session (see Fig. 4) and did not produce long-term dysfunction in the amygdala.

\section{Protein synthesis autoradiography}

The differential effect of protein synthesis inhibition in the auditory thalamus and amygdala on auditory fear conditioning is surprising in light of the many studies implicating thalamic plasticity in auditory fear conditioning. Although we infused a maximal dose of anisomycin into each brain area, it is possible that the degree of protein synthesis inhibition was different in the amygdala and thalamus. To assess this possibility, we used radiotracer autoradiography to assess the effect of intra-thalamic and intra-amygdala anisomycin on the incorporation of $\left[{ }^{14} \mathrm{C}\right]$-leucine, which indexes cerebral protein synthesis.

As shown in Fig. 5, both intra-amygdala and intra-thalamic anisomycin infusions produced a marked inhibition of protein synthesis within one hour after administration. The incorporation of $\left[{ }^{14} \mathrm{C}\right]-$ leucine was reduced through widespread areas of the brain centred around the amygdala and auditory thalamus, respectively. Intra-amygdala infusions of anisomycin inhibited protein synthesis throughout the entire amygdala, including the lateral and basolateral nuclei, central nucleus, basomedial nucleus, cortical and medial nuclei, and adjacent temporal neocortex and ventral striatum. Intra-thalamic anisomycin infusions inhibited protein synthesis in the entire auditory thalamus, including the medial geniculate nucleus, suprageniculate nucleus, and posterior intralaminar nucleus. The ventral hippocampus adjacent to the medial geniculate body also exhibited robust inhibition of protein synthesis.

Importantly, quantification of $\left[{ }^{14} \mathrm{C}\right]$-leucine incorporation in the amygdala and auditory thalamus of the infused and control hemispheres revealed similar inhibition of protein synthesis in the two brain
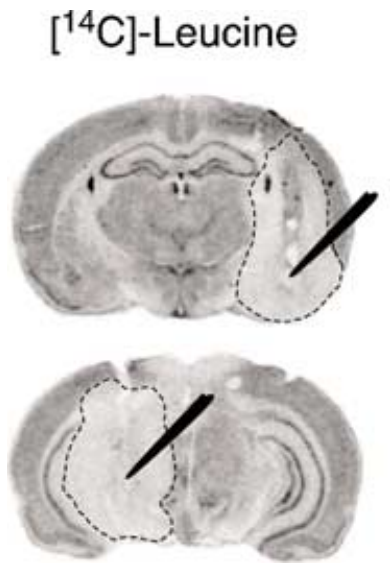

Cresyl violet

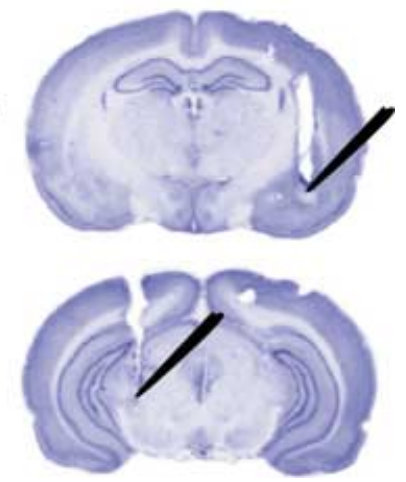

FIG. 5. Representative coronal sections from a rat infused with anisomycin $(62.5 \mu \mathrm{g}$ in $0.5 \mu \mathrm{L}$ ) into the amygdala (right hemisphere) and auditory thalamus (left hemisphere). The autoradiographs (left) indicate $\left[{ }^{14} \mathrm{C}\right]$-leucine incorporation and index cerebral protein synthesis in the amygdala (top) and auditory thalamus (bottom). The reduction of $\left[{ }^{14} \mathrm{C}\right]$-leucine uptake in the amygdala and auditory thalamus (affected regions bounded by dashed lines) indicates protein synthesis inhibition in the two brain areas after intra-cranial infusions of anisomycin. The coronal sections shown in the autoradiographs were stained with cresyl violet to visualize neuronal cell bodies. The cresyl-stained sections (right) reveal tissue damage caused by implantation of the guide cannulae and injectors, but anisomycin infusion itself did not produce any obvious pathology in the infused brain areas. 


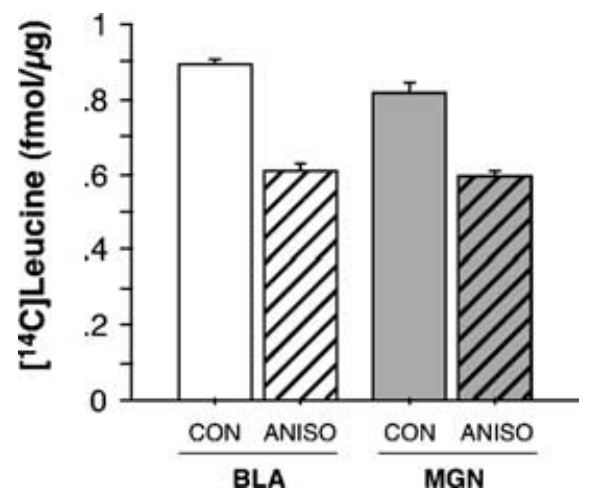

FIG. 6. Mean $( \pm \mathrm{SEM})\left[{ }^{14} \mathrm{C}\right]$-leucine incorporation measured in the BLA and MGN of anisomycin-treated rats. For each rat and brain region, densitometric radiotracer concentration measurements were made in several serial sections from $600-\mu \mathrm{m}$ rostral and $600-\mu \mathrm{m}$ caudal to the injection sites. For each brain region, measurements were made in both the anisomycin-treated hemisphere (ANISO) and the contralateral control hemisphere (CON). Individual rats were infused with anisomycin into both the MGN and BLA in opposite hemispheres. Anisomycin infusions produced a robust and statistically equivalent reduction in protein synthesis in the MGN and BLA.

areas (Fig. 6). This was revealed by a significant main effect of hemisphere (infused vs. control) in the ANOVA $\left(F_{1,2}=642.5\right.$, $P<0.002)$, but a nonsignificant $(P>0.15)$ main effect of brain region or interaction of brain region and hemisphere. Mean optical densities in the anisomycin-treated amygdala and thalamus were $68 \%$ and $73 \%$, respectively, of those in the contralateral control hemispheres. These results reveal that the dose of anisomycin used in the present studies yields similar, albeit widespread, inhibition of protein synthesis in the region of the amygdala and auditory thalamus.

It should be noted that we did not quantify the time course of the anisomycin-induced suppression of protein synthesis in the amygdala and auditory thalamus. Indeed, our data only provide a snapshot of protein synthesis in the brain one hour after intra-cranial infusions of anisomycin. It is possible that inhibition of protein synthesis is much greater shortly after drug infusion, and that considerable recovery of protein synthesis has occurred one hour following the infusion. Moreover, it is also conceivable that the region of protein synthesis inhibition is more discrete shortly after the infusion, and enlarges as anisomycin diffuses to neighbouring brain areas. Nevertheless, the failure of intra-thalamic infusions of anisomycin to impair auditory fear conditioning does not appear to be due to an inability of anisomycin to inhibit thalamic protein synthesis.

\section{Discussion}

The present study examined the role of protein kinase activation and protein synthesis in the auditory thalamus on the acquisition and consolidation of Pavlovian fear conditioning in rats. Despite the important role for auditory thalamic synaptic transmission in the acquisition of auditory fear conditioning, inhibition of protein kinases or protein synthesis in the auditory thalamus did not affect the acquisition or consolidation of auditory fear memories. In contrast, protein synthesis inhibition in the amygdala and adjacent neocortex prevented consolidation of long-term fear memories for both auditory and contextual stimuli. Several recent reports reveal a similarly important role for amygdaloid kinases in the acquisition of Pavlovian fear conditioning (Goosens et al., 2000; Schafe \& LeDoux, 2000; Schafe et al., 2000; Lin et al., 2001). Collectively, these data support the hypothesis that protein synthesis-dependent synaptic plasticity in the amygdala is an essential mechanism for the establishment of long-term fear memory (Maren, 1999a; Blair et al., 2001; Schafe et al., 2001). Nonetheless, it is important to appreciate that antibiotics such as anisomycin may also affect memory by inhibiting catecholamine synthesis (e.g. Flexner \& Goodman, 1975).

It is surprising that intra-thalamic infusions of anisomycin did not affect auditory fear conditioning given the large body of literature implicating MGN plasticity in auditory fear conditioning (Supple \& Kapp, 1989; Edeline \& Weinberger, 1991; 1992). It is possible that the dose of anisomycin we infused into the auditory thalamus was not sufficient to yield behavioural deficits. Yet because this dose is effective when infused into the amygdala, one might posit that the amygdala and thalamus are differentially sensitive to protein synthesis inhibitors to account for the present results by this view. This does not seem likely, however, insofar as our autoradiographic quantification of protein synthesis revealed similar levels of $\left[{ }^{14} \mathrm{C}\right]$-leucine uptake after anisomycin infusion into each brain area. Nonetheless, it is conceivable that residual protein synthesis in the thalamus, but not amygdala, was sufficient for fear conditioning, because protein synthesis was only modestly reduced in both brain areas at the time point we measured. Examining the dose-response relationships between intra-thalamic and intra-amygdala infusion of these drugs and the acquisition of conditional fear may answer these questions. But because the dose of anisomycin we have chosen is near maximal, it is likely that nonspecific effects of high doses of these drugs would confound interpretation of the behavioural results.

Although we failed to observe a disruption of fear conditioning after protein kinase inhibition in the auditory thalamus, a recent report indicates that an inhibitor of MEK kinase, an upstream regulator of extracellular-regulated kinase (ERK/MAPK), impairs the acquisition of auditory fear conditioning (Shoute et al., 2002). This same study found, as we have reported, that post-training anisomycin infusions into the auditory thalamus did not affect the consolidation of auditory fear conditioning. Hence, it is conceivable that the thalamic protein kinases inhibited by $\mathrm{H} 7$ infusions (protein kinase $\mathrm{A}$ and $\mathrm{C}$ ) in the present study are not involved in the acquisition of auditory fear conditioning, but that other kinases not affected by H7, such as MEK, ERK/MAPK and calcium-calmodulin kinase are involved in the acquisition of auditory fear memories. If so, this would suggest an interesting role for signal transduction cascades in the auditory thalamus in the formation of fear memories that are ultimately stored elsewhere in the brain.

The failure of protein synthesis inhibition in the auditory thalamus to affect fear conditioning suggests that long-term synaptic plasticity in the thalamus is not essential for establishing fear CRs. Alternatively, synaptic plasticity in the auditory thalamus may support changes in CS processing that accompany, but are not critical, to the acquisition of the CS-US associations that drive conditional fear responses. For example, MGN neurons exhibit receptive field plasticity during auditory fear conditioning (Edeline \& Weinberger, 1991, 1992). In this case, MGN neurons, like neurons in the auditory cortex (Edeline et al., 1993), shift their best firing frequencies to the frequency of the CS used for auditory fear conditioning. This form of plasticity sharpens generalization gradients around the CS, allowing for selective responding to the auditory frequency paired with shock. Receptive field plasticity is also critical for discriminative conditioning, in which two different CSs signal the presence ( $\mathrm{CS}+$ ) and the absence (CS-) of the US. Hence, receptive field plasticity in the MGN may be important for supporting generalization and discrimination to discrete auditory CSs, but may not be critical for the generation of CS-elicited fear responses. Further studies are required to determine whether disruption of auditory thalamic synaptic plasticity affects the acquisition of auditory discriminations and other behavioural phenomena that depend on thalamic receptive field plasticity. 
In agreement with other reports (Nader et al., 2000; Schafe \& LeDoux, 2000), the present results reveal that inhibition of protein synthesis in the amygdala impairs the consolidation of auditory fear memories. An intriguing possibility is that amygdala protein synthesis is also required for the establishment of associative plasticity in the auditory thalamus and other brain regions during fear conditioning. Consistent with this possibility, two recent studies have found that animals conditioned after inactivation of the amygdala with muscimol do not exhibit increases in CS-elicited spike firing in the MGN that normally accompany conditioning to auditory CSs (Maren et al., 2001; Poremba \& Gabriel, 2001). Thus, the amygdala appears to be essential not only for the acquisition of fear memory, but also for the induction of neuronal correlates of this learning in other brain structures including the MGN. These data suggest that neuronal plasticity in the auditory thalamus is initiated by amygdala activity during fear conditioning (Poremba \& Gabriel, 2001), although consolidation processes occurring in the amygdala after conditioning might also be involved in establishing long-term thalamic plasticity. An important question, then, is whether post-training inhibition of protein synthesis in the amygdala impairs thalamic plasticity in the same way as muscimol inactivation of the amygdala does during fear conditioning.

Our results extend several recent studies that indicate that protein synthesis in the amygdala is involved in auditory fear conditioning (Nader et al., 2000; Schafe \& LeDoux, 2000). That is, our results reveal that both auditory and contextual fear conditioning require amygdaloid protein synthesis, which is not surprising given the extensive literature implicating amygdala neurons in both forms of learning (Maren et al., 1996a; Maren, 1998, 1999b; Goosens \& Maren, 2001). Nonetheless, we have recently demonstrated that contextual fear conditioning can be acquired in rats with neurotoxic BLA lesions when an extensive overtraining procedure is administered (75 context-shock trials; Maren, 1999b). It would be of interest to determine whether overtraining affects the ability of post-training protein synthesis inhibitors to impair the consolidation of contextual fear. Indeed, recent studies indicate that the pattern of training, for example whether trials are massed or spaced, affects the ability of systemic anisomycin to disrupt fear conditioning (Bourtchouladze et al., 1998; Scharf et al., 2002).

The present data are consistent with a model whereby long-term fear memory is encoded by synaptic modifications that depend on protein synthesis and gene transcription (Blair et al., 2001; Schafe et al., 2001). A candidate cellular mechanism underlying these synaptic modifications is amygdaloid LTP (Maren, 1999a; Goosens \& Maren, 2002). LTP induction in the amygdala requires NMDA receptor activation (Maren \& Fanselow, 1995; Huang \& Kandel, 1998; Bauer et al., 2002), and activation of voltage-gated calcium channels under some conditions (Bauer et al., 2002). Activation of protein kinases, such as PKA and MAPK (Huang et al., 2000), calcium calmodulin kinase IV (Wei et al., 2002), and PI-3 kinase (Lin et al., 2001) are also involved in LTP induction in the amygdala. Moreover, inhibition of protein synthesis abolishes late-phase LTP in the amygdala (Huang et al., 2000). Fear conditioning is associated with LTP-like changes in synaptic potentials (McKernan \& Shinnick-Gallagher, 1997; Rogan et al., 1997), and behavioural contingencies that degrade learning also degrade amygdaloid LTP induction (Bauer et al., 2001). Long-term fear memory is attenuated by intra-amygdala infusions of NMDA receptor antagonists (Miserendino et al., 1990; Maren et al., 1996b; Lee \& Kim, 1998; Rodrigues et al., 2001; Bauer et al., 2002), voltagegated calcium channel blockers (Bauer et al., 2002), protein kinase inhibitors (Goosens et al., 2000; Schafe \& LeDoux, 2000; Schafe et al., 2000; Lin et al., 2001), inhibitors of protein synthesis (present data; Nader et al., 2000; Schafe \& LeDoux, 2000) and gene transcription
(Bailey et al., 1999). Moreover, genetically modified mice that lack key proteins required for LTP induction in the amygdala exhibit impairments in fear conditioning (Brambilla et al., 1997; Wei et al., 2002).

An unexpected finding to emerge from the present study was the extensive area of protein synthesis inhibition generated by intra-cranial anisomycin infusions. That is, infusion of an anisomycin dose used in previously published reports (Nader et al., 2000; Schafe \& LeDoux, 2000) produced a significant region of protein synthesis inhibition that included not only the target nuclei in the thalamus and amygdala, but also adjacent nuclei and brain structures. Surprisingly, there has been little autoradiographic work to examine the spatial profile of protein synthesis inhibition after intra-cranial infusions of protein synthesis inhibitors. Eichenbaum et al. (1973) reported restricted regions of protein synthesis inhibition after infusions of either puromycin or cycloheximide in the monkey brain. Similarly, intra-amygdala infusions of low doses of cycloheximide produce a restricted pattern of protein synthesis inhibition in rat brain (Kesner et al., 1981). Yet, in the light of the present data, we cannot rule out the possibility that the impairments in fear conditioning reported in this and other studies is due to inhibition of protein synthesis in non-neuronal cells or in brain areas adjacent to the amygdala. Indeed, it is possible that protein synthesis inhibition in the adjacent auditory cortex, for example, contributed to the observed memory deficits. Inhibition of protein synthesis in the gerbil auditory cortex has been reported to disrupt the consolidation of conditioned auditory discriminations (Kraus et al., 1999; Kraus et al., 2000; Kraus et al., 2002). Hence, further work is required to develop an anisomycin infusion regimen that produces a focal (nucleus-specific) inhibition of protein synthesis in rats. In this regard, autoradiographic mapping of cerebral metabolic processes will be an essential tool for mapping the spatial and temporal profile of intra-cranial drug infusions.

It is also important to point out that our autoradiographic analysis of $\left[{ }^{14} \mathrm{C}\right]$-leucine incorporation indicated that intra-cranial anisomycin produced a moderate (27-32\%) suppression of protein synthesis. It is possible that this degree of inhibition is more deleterious to amygdala function than to thalamic function, thus accounting for the differential behavioural effects of thalamic and amygdaloid protein synthesis inhibition. Moreover, inspection of the autoradiograms revealed focal areas within the BLA where protein synthesis was less than $50 \%$ of the control hemisphere; such areas were not observed in the MGN. Thus, there may have been subtle differences in both the degree and functional consequences of protein synthesis inhibition in the two brain areas that contributed to the behavioural effects.

Nonetheless, our finding that the consolidation of fear memory is disrupted by inhibition of protein synthesis in the amygdala, but not the auditory thalamus, has important implications for understanding the cellular and neural mechanisms of fear memory. It suggests that the molecular machinery underlying the long-term synaptic plasticity that accompanies fear conditioning may not be widely distributed throughout the fear conditioning circuit. Rather, the synaptic plasticity underlying fear CRs may be localized to circuitry within the amygdaloid complex. This discovery constrains neurobiological models of fear conditioning, and uncovers a neural target for molecular and pharmacological manipulations designed to either enhance or impair the consolidation of aversive memory.

\section{Acknowledgements}

This work was supported by a grant from the National Institute of Mental Health (R29MH57865 and R01MH065961) to SM. We thank Tyler C. Brown for technical assistance. 


\section{Abbreviations}

ANISO, anisomycin; ANOVA, analysis of variance; APV, 2-amino-5-phosphonopentanoic acid; BLA, basolateral amygdala; CS, conditional stimulus; LTP, long-term potentiation; H7, 1-(5'-isoquinolinesulphonyl)-2-methylpiperazine; MAPK, mitogen-activated protein kinase; MGN, medial geniculate nucleus; NMDA, $N$-methyl-D-aspartate; PBS, phosphate-buffered saline; PKA, protein kinase A; US, unconditional stimulus.

\section{References}

Bailey, D.J., Kim, J.J., Sun, W., Thompson, R.F. \& Helmstetter, F.J. (1999) Acquisition of fear conditioning in rats requires the synthesis of mRNA in the amygdala. Behav. Neurosci., 113, 276-282.

Bauer, E.P., LeDoux, J.E. \& Nader, K. (2001) Fear conditioning and LTP in the lateral amygdala are sensitive to the same stimulus contingencies. Nature Neurosci., 4, 687-688.

Bauer, E.P., Schafe, G.E. \& LeDoux, J.E. (2002) NMDA receptors and L-type voltage-gated calcium channels contribute to long-term potentiation and different components of fear memory formation in the lateral amygdala. J. Neurosci., 22, 5239-5249.

Blair, H.T., Schafe, G.E., Bauer, E.P., Rodrigues, S.M. \& LeDoux, J.E. (2001) Synaptic plasticity in the lateral amygdala: a cellular hypothesis of fear conditioning. Learn. Mem., 8, 229-242.

Bourtchouladze, R., Abel, T., Berman, N., Gordon, R., Lapidus, K. \& Kandel, E.R. (1998) Different training procedures recruit either one or two critical periods for contextual memory consolidation, each of which requires protein synthesis and PKA. Learn. Mem., 5, 365-374.

Brambilla, R., Gnesutta, N., Minichiello, L., White, G., Roylance, A.J., Herron, C.E., Ramsey, M., Wolfer, D.P., Cestari, V., Rossi-Arnaud, C., Grant, S.G., Chapman, P.F., Lipp, H.P., Sturani, E. \& Klein, R. (1997) A role for the Ras signalling pathway in synaptic transmission and long-term memory. Nature, 390, 281-286.

Brunzell, D.H. \& Kim, J.J. (2001) Fear conditioning to tone, but not to context, is attenuated by lesions of the insular cortex and posterior extension of the intralaminar complex in rats. Behav. Neurosci., 115, 365-375.

Campeau, S. \& Davis, M. (1995) Involvement of subcortical and cortical afferents to the lateral nucleus of the amygdala in fear conditioning measured with fear-potentiated startle in rats trained concurrently with auditory and visual conditioned stimuli. J. Neurosci., 15, 2312-2327.

Davis, M. (2000) The role of the amygdala in conditioned and unconditioned fear and anxiety. In Aggleton, J.P., (Ed), The Amygdala: a Functional Analysis. Oxford University Press, New York, pp. 213-287.

Edeline, J.M., Pham, P. \& Weinberger, N.M. (1993) Rapid development of learning-induced receptive field plasticity in the auditory cortex. Behav. Neurosci., 107, 539-551.

Edeline, J.M. \& Weinberger, N.M. (1991) Subcortical adaptive filtering in the auditory system: associative receptive field plasticity in the dorsal medial geniculate body. Behav. Neurosci., 105, 154-175.

Edeline, J.M. \& Weinberger, N.M. (1992) Associative retuning in the thalamic source of input to the amygdala and auditory cortex: receptive field plasticity in the medial division of the medial geniculate body. Behav. Neurosci., 106, $81-105$.

Eichenbaum, H., Butter, C.M. \& Agranoff, B.W. (1973) Radioautographic localization of inhibition of protein synthesis in specific regions of monkey brain. Brain Res., 61, 438-441.

Fanselow, M.S. \& LeDoux, J.E. (1999) Why we think plasticity underlying Pavlovian fear conditioning occurs in the basolateral amygdala. Neuron, 23, 229-232.

Fendt, M. \& Fanselow, M.S. (1999) The neuroanatomical and neurochemical basis of conditioned fear. Neurosci. Biobehav. Rev., 23, 743-760.

Flexner, L.B. \& Goodman, R.H. (1975) Studies on memory: inhibitors of protein synthesis also inhibit catecholamine synthesis. Proc. Natl Acad. Sci. (USA), 72, 4660-4663.

Gabriel, M., Saltwick, S.E. \& Miller, J.D. (1975) Conditioning and reversal of short-latency multiple-unit responses in the rabbit medial geniculate nucleus. Science, 189, 1108-1109.

Gerren, R.A. \& Weinberger, N.M. (1983) Long-term potentiation in the magnocellular medial geniculate nucleus of the anesthetized cat. Brain Res., 265, 138-142.

Goosens, K.A., Holt, W. \& Maren, S. (2000) A role for amygdaloid PKA and $\mathrm{PKC}$ in the acquisition of long-term conditional fear memories in rats. Behav. Brain Res., 114, 145-152.
Goosens, K.A. \& Maren, S. (2001) Contextual and auditory fear conditioning are mediated by the lateral, basal, and central amygdaloid nuclei in rats. Learn. Mem., 8, 148-155.

Goosens, K.A. \& Maren, S. (2002) Long-term potentiation as a substrate for memory: Evidence from studies of amygdaloid plasticity and Pavlovian fear conditioning. Hippocampus, 12, 592-599.

Huang, Y.Y. \& Kandel, E.R. (1998) Postsynaptic induction and PKA-dependent expression of LTP in the lateral amygdala. Neuron, 21, 169-178.

Huang, Y.Y., Martin, K.C. \& Kandel, E.R. (2000) Both protein kinase a and mitogen-activated protein kinase are required in the amygdala for the macromolecular synthesis-dependent late phase of long-term potentiation. J. Neurosci., 20, 6317-6325.

Impey, S., Smith, D.M., Obrietan, K., Donahue, R., Wade, C. \& Storm, D.R. (1998) Stimulation of cAMP response element (CRE)-mediated transcription during contextual learning. Nature Neurosci., 1, 595-601.

Jarrell, T.W., Romanski, L.M., Gentile, C.G., McCabe, P.M. \& Schneiderman, N. (1986) Ibotenic acid lesions in the medial geniculate region prevent the acquisition of differential Pavlovian conditioning of bradycardia to acoustic stimuli in rabbits. Brain Res., 382, 199-203.

Josselyn, S.A., Shi, C.J., Carlezon, W.A., Neve, R.L., Nestler, E.J. \& Davis, M. (2001) Long-term memory is facilitated by cAMP response element-binding protein overexpression in the amygdala. J. Neurosci., 21, 2404-2412.

Kesner, R.P., Partlow, L.M., Bush, L.G. \& Berman, R.F. (1981) A quantitative regional analysis of protein synthesis inhibition in the rat brain following localized injection of cycloheximide. Brain Res., 209, 159-176.

Kraus, M., Grimm, R., Schicknick, H., Wetzel, W., Staak, S., Scheich, H. \& Tischmeyer, W. (1999) Protein synthesis in the gerbil auditory cortex is required for the formation of memory for frequency modulations. J. Neurochem., 73, S42-S42.

Kraus, M., Schicknick, H., Grimm, R., Wetzel, W., Staak, S., Scheich, H. \& Tischmeyer, W. (2000) Auditory memory formation in the gerbil is sensitive to protein synthesis inhibitors applied to the auditory cortex. Eur. J. Neurosci., 12, 203-203.

Kraus, M., Schicknick, H., Wetzel, W., Ohl, F., Staak, S. \& Tischmeyer, W. (2002) Memory consolidation for the discrimination of frequency-modulated tones in Mongolian gerbils is sensitive to protein-synthesis inhibitors applied to the auditory cortex. Learn. Mem., 9, 293-303.

LeDoux, J.E. (2000) Emotion circuits in the brain. Annu. Rev. Neurosci., 23, $155-184$.

LeDoux, J.E., Iwata, J., Pearl, D. \& Reis, D.J. (1986) Disruption of auditory but not visual learning by destruction of intrinsic neurons in the rat medial geniculate body. Brain Res., 371, 395-399.

Lee, H. \& Kim, J.J. (1998) Amygdala NMDA receptors are critical for new fear learning in previously fear-conditioned rats. J. Neurosci., 18, $8444-8454$

Lin, C.H., Yeh, S.H., Lin, C.H., Lu, K.T., Leu, T.H., Chang, W.C. \& Gean, P.W. (2001) A role for the PI-3 kinase signaling pathway in fear conditioning and synaptic plasticity in the amygdala. Neuron, 31, 841-851.

Maren, S. (1998) Overtraining does not mitigate contextual fear conditioning deficits produced by neurotoxic lesions of the basolateral amygdala. $J$. Neurosci., 18, 3088-3097.

Maren, S. (1999a) Long-term potentiation in the amygdala: a mechanism for emotional learning and memory. TINS, 22, 561-567.

Maren, S. (1999b) Neurotoxic basolateral amygdala lesions impair learning and memory but not the performance of conditional fear in rats. J. Neurosci., 19, 8696-8703.

Maren, S. (2001) Neurobiology of Pavlovian fear conditioning. Annu. Rev. Neurosci., 24, 897-931.

Maren, S., Aharonov, G. \& Fanselow, M.S. (1996a) Retrograde abolition of conditional fear after excitotoxic lesions in the basolateral amygdala of rats: absence of a temporal gradient. Behav. Neurosci., 110, 718-726.

Maren, S., Aharonov, G., Stote, D.L. \& Fanselow, M.S. (1996b) N-methyl-Daspartate receptors in the basolateral amygdala are required for both acquisition and expression of conditional fear in rats. Behav. Neurosci., 110, 1365-1374.

Maren, S. \& Fanselow, M.S. (1995) Synaptic plasticity in the basolateral amygdala induced by hippocampal formation stimulation in vivo. J. Neurosci., 15, 7548-7564.

Maren, S. \& Fanselow, M.S. (1996) The amygdala and fear conditioning: Has the nut been cracked? Neuron, 16, 237-240.

Maren, S., Yap, S.A. \& Goosens, K.A. (2001) The amygdala is essential for the development of neuronal plasticity in the medial geniculate nucleus during auditory fear conditioning in rats. J. Neurosci., 21, RC135.

McEchron, M.D., Green, E.J., Winters, R.W., Nolen, T.G., Schneiderman, N. \& McCabe, P.M. (1996) Changes of synaptic efficacy in the medial geniculate 
nucleus as a result of auditory classical conditioning. J. Neurosci., 16, $1273-1283$.

McKernan, M.G. \& Shinnick-Gallagher, P. (1997) Fear conditioning induces a lasting potentiation of synaptic currents in vitro. Nature (Lond.), 390, 607-611.

Miserendino, M.J., Sananes, C.B., Melia, K.R. \& Davis, M. (1990) Blocking of acquisition but not expression of conditioned fear-potentiated startle by NMDA antagonists in the amygdala. Nature (Lond.), 345, 716-718.

Nader, K., Schafe, G.E. \& LeDoux, J.E. (2000) Fear memories require protein synthesis in the amygdala for reconsolidation after retrieval. Nature (Lond.), 406, 722-726.

Poremba, A. \& Gabriel, M. (1997) Medial geniculate lesions block amygdalar and cingulothalamic learning-related neuronal activity. J. Neurosci., 17, $8645-8655$.

Poremba, A. \& Gabriel, M. (2001) Amygdalar efferents initiate auditory thalamic discriminative training-induced neuronal activity. J. Neurosci. 21, 270-278.

Rodrigues, S.M., Schafe, G.E. \& LeDoux, J.E. (2001) Intra-amygdala blockade of the NR2B subunit of the NMDA receptor disrupts the acquisition but not the expression of fear conditioning. J. Neurosci., 21, 6889-6896.

Rogan, M.T., Staubli, U.V. \& LeDoux, J.E. (1997) Fear conditioning induces associative long-term potentiation in the amygdala. Nature (Lond.), 390 , 604-607.

Schafe, G.E., Atkins, C.M., Swank, M.W., Bauer, E.P., Sweatt, J.D. \& LeDoux, J.E. (2000) Activation of ERK/MAP kinase in the amygdala is required for memory consolidation of Pavlovian fear conditioning. J. Neurosci., 20, 8177-8187.

Schafe, G.E. \& LeDoux, J.E. (2000) Memory consolidation of auditory Pavlovian fear conditioning requires protein synthesis and protein kinase A in the amygdala. J. Neurosci., 20, RC96.
Schafe, G.E., Nader, K., Blair, H.T. \& LeDoux, J.E. (2001) Memory consolidation of Pavlovian fear conditioning: a cellular and molecular perspective. TINS, 24, 540-546.

Scharf, M.T., Woo, N.H., Lattal, K.M., Young, J.Z., Nguyen, P.V. \& Abel, T. (2002) Protein synthesis is required for the enhancement of long-term potentiation and long-term memory by spaced training. J. Neurophysiol., 87, 2770-2777

Shoute, A.M., Choi, J.S., LeDoux, J.E. \& Schafe, G.E. (2002) The auditory thalamus contributes to memory formation of auditory fear conditioning via the ERK/MAP kinase signaling pathway. Soc. Neurosci. Abstract., 85.9.

Smith, C.B., Crane, A.M., Kadekaro, M., Agranoff, B.W. \& Sokoloff, L. (1984) Stimulation of protein synthesis and glucose utilization in the hypoglossal nucleus induced by axotomy. J. Neurosci., 10, 2489-2496.

Supple, W. Jr \& Kapp, B.S. (1989) Response characteristics of neurons in the medial component of the medial geniculate nucleus during Pavlovian differential fear conditioning in rabbits. Behav. Neurosci., 103, 1276-1286.

Swanson, L.W. (1998) Brain Maps: Structure of the Rat Brain. Elsevier, Amsterdam.

Webber, T.J., Green, E.J., Winters, R.W., Schneiderman, N. \& McCabe, P.M. (1999) Contribution of NMDA and non-NMDA receptors to synaptic transmission from the brachium of the inferior colliculus to the medial subdivision of the medial geniculate nucleus in the rabbit. Exp. Brain. Res., 124, 295-303.

Wei, F., Qiu, C.S., Liauw, J., Robinson, D.A., Ho, N., Chatila, T. \& Zhuo, M. (2002) Calcium-calmodulin-dependent protein kinase IV is required for fear memory. Nature Neurosci., 5, 573-579.

Weinberger, N.M. (1998) Physiological memory in primary auditory cortex: characteristics and mechanisms. Neurobiol. Learn. Mem., 70, 226-251. 